\title{
LA-UR-16-26733
}

Approved for public release; distribution is unlimited.

Title: $\quad$ Learning Team Review 2016-0002 Parking Lot Event 2016

Author(s): $\quad$ Wilburn, Dianne Williams

Bitteker, Leo John Jr.

Brooks, Melynda Louise

Romero-Trujillo, Natalie

Currie, Scott Allister

Martin, Joanne Skrivan

Sondheim, Walter E.

Tovesson, Fredrik

Young, Jennifer S.

Crespin, Thomas Joe

Intended for: Web

Issued: 
Disclaimer:

Los Alamos National Laboratory, an affirmative action/equal opportunity employer, is operated by the Los Alamos National Security, LLC for the National Nuclear Security Administration of the U.S. Department of Energy under contract DE-AC52-06NA25396. By approving this article, the publisher recognizes that the U.S. Government retains nonexclusive, royalty-free license to publish or reproduce the published form of this contribution, or to allow others to do so, for U.S. Government purposes. Los Alamos National Laboratory requests that the publisher identify this article as work performed under the auspices of the U.S. Department of Energy. Los Alamos National Laboratory strongly supports academic freedom and a researcher's right to publish; as an institution, however, the Laboratory does not endorse the viewpoint of a publication or guarantee its technical correctness. 


\section{Learning Team Review 2016-0002 \\ Parking Lot Event 2016}

\section{Introduction:}

The purpose of a Learning Team is to transfer and communicate the information into operational feedback and improvement. We want to pay attention to the small things that go wrong because they are often early warning signals and may provide insight into the health of the whole system.

\section{Brief Description of Event:}

P-25 staff were expecting a delivery of concrete shielding blocks. On May 19, 2016, Employee $1, \mathrm{E}-1$, received a call from the shielding block manufacturing company to notify him the blocks were loaded and enroute for delivery to LANL. The shielding blocks manufacturing company informed E-1 that the company's truck and driver who usually delivered were not available and a new trucking company would be delivering the shipment on May 20, 2016. E-1 proceeded to prepare the necessary paperwork for the driver to enter TA-53. E-1 had a doctor's appointment the morning of the delivery, so he notified Employee 2, E-2, of the situation. E-1 called dispatch at the trucking company to give them E-2's contact information. After finishing at the doctor's office on the morning of May 20, E-1 turned on his phone and received a call from the TA-53 visitor's desk staff informing E-1 that the driver had entered the site but had not reported to the desk. E-1 and E-2 met with the driver at the parking area in front of building 1, all necessary entry requirements had been completed. At this point E-1 and E-2, escorted him down to where these blocks would be unloaded. The semi-truck driver was directed to a location adjacent to a series of transportainers in a parking lot across from experimental area-B. E-1 was to operate the forklift and E-2 would serve as the spotter.

During the time E-1, E-2, and the new truck driver were arriving in the parking lot, two vans were enroute to the same parking lot with LANL employees and visitors. The drivers of the two vans will be referenced to as Driver 1 and Driver 2, D-1 and D-2. During the following events, the weather was overcast and rainy, which contributed to poor visibility.

Just before D1 entered the parking lot, E-2 communicated to E-1 to pause the work so they could talk about the initial plan for unloading the shielding blocks. E-1 exited the forklift without lowering the tines and started to walk over to where E-2 was standing to discuss the initial plan.

When E-1 was near the tips of the tines on the left side of the forklift and E-2 was standing in the area near the tires on the left side of the trailer bed where the shielding blocks were to be removed from during unloading, the first van driven by D-1drove through the area going 


\section{Learning Team Review 2016-0002 \\ Parking Lot Event May 2016}

between E-1 on the van's left and E-2 standing on the van's right. E-1 moved from standing next to the forklift on the van's left and crossed the parking lot to E-2 who was standing next to the delivery truck to the van's right to discuss the initial plan for unloading the blocks.

At this point in time, the second driver, D-2, entered the parking lot, observing the truck load of shielding blocks and E-1, E-2, and the truck driver on the right side of the roadway. D-2 did not observe the forklift on the left or its raised tines. D-2 took a wide turn to avoid E-1, E-2 and the truck driver. At that point, the van collided with the raised forklift tines.

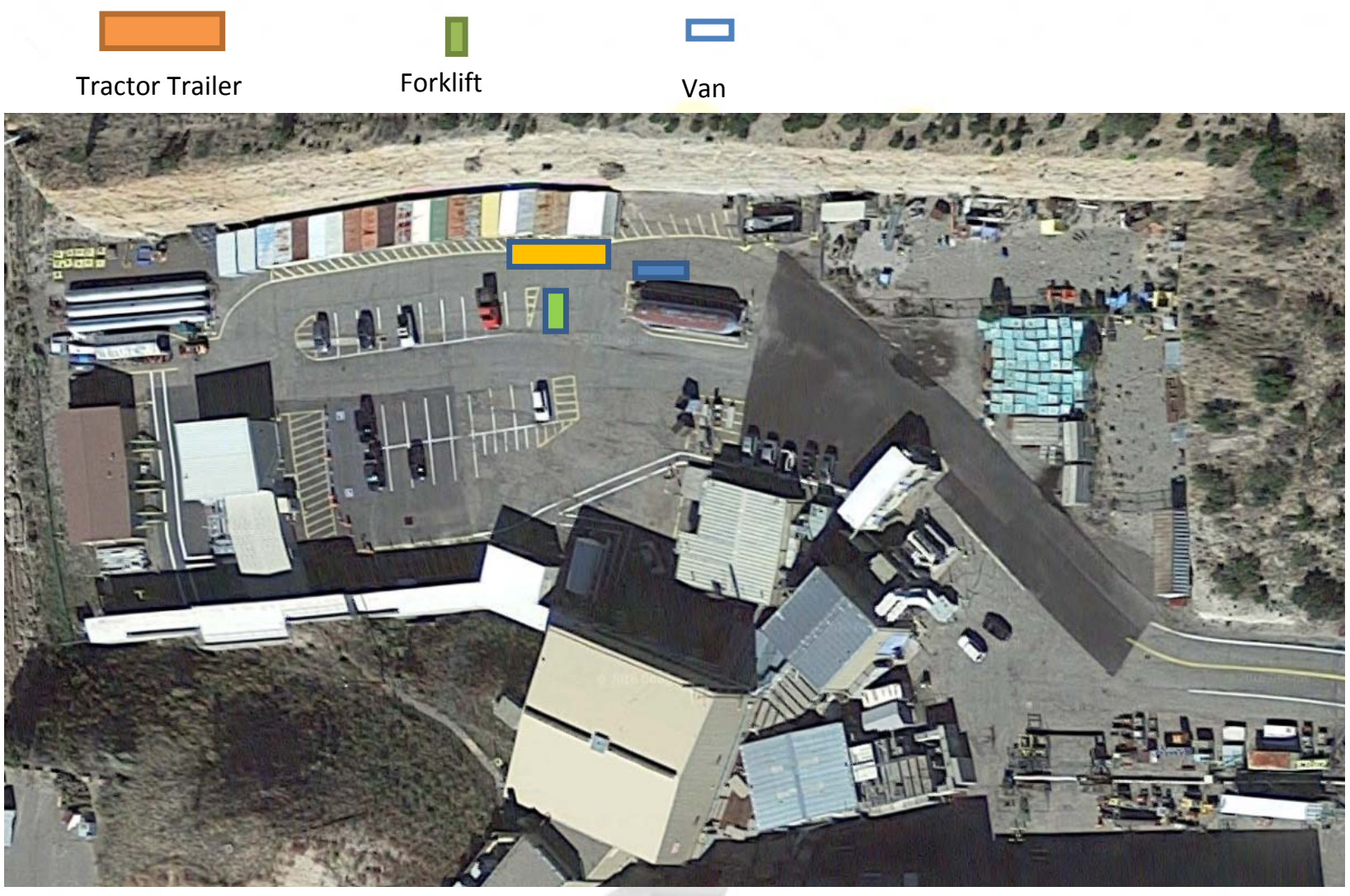




\section{Fact Finding Results:}

As a result of the incident described above, the learning team has been tasked with determining the following:

\section{What's important for us to know? How did this event happen?}

The following existing conditions were (may have been) contributing factors to the incident:

- A large tank and office trailer impair view of oncoming traffic and pedestrians.

- Employees felt stressed.

- The visitors were not aware of forklift activities in the area and the forklift operators were not aware of the planned tour so neither was expecting the other in the area

- The rainy overcast day contributed to the poor visibility of the forklift tines

\section{How was the organization managing the hazard?}

- Forklift operators are required to have specific training.

- Employees are trained in the ISM 5-Step process.

\section{What failed? What worked? What tools would have helped prevent this event?} What Failed?

- Employees were performing work in a parking lot.

- Multiple tasks were occurring in the parking lot: vehicle traffic and an unloading operation.

- A mirror for blind spots had been purchased but funding was not available to install it correctly.

- No signs, cones or people were used to convey to oncoming traffic that forklift operations were in progress or to direct traffic away from the forklift operations.

- Forklift operator did not lower tines of forklift before exiting the forklift because he thought the short amount of time the tines would be up while he had a brief conversation would not expose them to any risks.

\section{What Worked?}

- The first driver saw the forklift because the driver E-1, was standing next to the forklift and the spotter E2 was standing next to the semi-trailer. 


\section{Learning Team Review 2016-0002 \\ Parking Lot Event May 2016}

What was surprising?

- How invisible the tines were in the weather

- How much the presence of pedestrians draws your attention away from the roadway

- It is easy to make an in the moment assessment that a risk is negligible (the tines could stay up for a very short period because no one would happen to drive by at that instant), but have the risk turn out to be very real.

- Everyone missed the warning at this point and continued with their business.

\section{Error Precursors:}

1) Task Demands; 2) Work Environment; 3) Individual Capabilities; 4) Human Nature Comments:

- Task Demands

- Time Pressure - Company delivering shielding blocks called E-1 the day before the delivery and said they were sending a new driver which required submitting paperwork and getting the appropriate approvals before the driver arrived the next day.

- Time Pressure - The delivery driver arrived earlier than anticipated.

- Simultaneous / multiple tasks - The tour group was unaware of the shielding block delivery activity in the parking lot and vice versa.

- E-1 and E-2 were concerned about the hourly rate for the truck driver and the cost to their project.

- Work Environment

- Work Arounds - The shielding block delivery was occurring in a parking lot because one of the two storage areas is at the edge of that parking lot, the other is just outside of the Area B roll-up door.. The storage area is there because it was the only nearby space available. Therefore, workers were performing their duties in a parking lot with vehicular traffic.

- Individual Capabilities

- Inexperience - Staff has forklift training but are not traffic safety SMEs.

- Imprecise communication habits - The visitors were not aware of forklift activities in the area and the forklift operators were not aware of the planned tour so neither was expecting the other in the area. 
- Human Nature

- $\quad$ Stress - D-2 was escorting higher levels staff from an outside organization for a higher level LANL manager.

- Stress - E1 did not lower the tines on the forklift.

- Habit Patterns - Staff did not put out traffic cones for the forklift activity because they did not properly recognize the hazards that the traffic path, signage and blind spots create around the tank while performing their work in this area of the parking lot..

- Mental Shortcuts - E1 did not lower the tines on the forklift because it would "just take a minute" to talk to E2.

\section{ISM Five Step Process:}

1) Define Scope of Work; 2) Work Environment; 3) Develop and Implement Controls;

4) Perform Work; 5) Ensure Performance/Feedback

Comments:

- Define Scope of Work - For most forklift operations, staff indicated they usually do a brief pre-job.

- Develop and Implement Controls - The staff working the shielding block delivery did not place traffic cones to create a safety zone or wear safety vests.

- Work Environment - Staff working with the shielding block delivery did not analyze co-existing hazards in the parking lot such as the unobstructed views.

\section{Pose the Following Question to Affected Employee:}

"What would you do differently in the future to prevent this from happening again"?

- Staff would have utilized traffic cones.

- Staff would have lowered the tines.

- Staff would have made sure to announce the activity at the site-wide Plan of the Day.

- If an employee is under a lot of stress or not feeling well, they would pause the job or ask another trained employee to perform in their place.

- Staff will be more cautious when driving in parking lots, especially those that are congested.

- The employees would have "taken 5 " for safety.

- Staff would not have been as concerned about the truck driver's hourly pay rate. 


\section{Learning Team Review 2016-0002 \\ Parking Lot Event May 2016}

\section{Organizational/System Issues:}

- Traffic mirror was bought by ADEPS WSST a few years ago. However, funding was not available for installation. Therefore, a technician installed the mirror, but it is not secure.

- There are a limited number of staff members trained as forklift drivers._Forklift training does not involve any discussion of steps to follow if performing forklift operations in an area that also has vehicular traffic.

- The parking lot is for parking, pedestrian traffic and storage. During experiments, the parking lot is extremely busy and not designed for the large volume of traffic.

- How do we encourage employees to "take 5?"

- Staff were rushed after the event to complete the on-scene investigation so the tour could continue.

- When staff change offices, they have an ergonomic evaluation. Similarly, perhaps as we change things in parking lots, we should review those areas for safety concerns because the hazards may have changed.

\section{Summary/Conclusion:}

Human Performance Improvement (HPI) is about reducing errors and managing defenses to prevent significant events. The objective of ISM is to perform work in a safe and environmentally sound manner. When work is to be conducted in a parking lot, a trained person designated by the institution should conduct a basic hazard assessment for the worksite. This safety professional should determine whether engineering, administrative, or personal protection measures should be implemented. Communications concerning co-mingling of activities is often missed due to things such as the work occurs infrequently or it is a change in an employee's usual routine. The facility can use the Plan of the Day meetings to help communicate information about tour groups. The parking lot for this event has several blind spots that need to be corrected. At a minimum, when employees are working in parking lots, they should consider flaggers and the use of traffic cones to keep vehicular traffic out of their work zone and safety vests to increase their visibility to others.

\section{Recommended Improvement Corrective Actions?}

1. Paint one way traffic arrows on the roadway around tank.

2. Enter an FSR to install a traffic mirror for blind spots.

3. Buy new traffic cones. The workers have traffic cones but they are aging and not very bright. The cones were used to block the area after the event. 


\section{Learning Team Review 2016-0002 \\ Parking Lot Event May 2016}

4. Include this event in training for laboratory forklift operators and include pictures from the event. Parking lot safety should be added to the curriculum in accordance with the Manual on Uniform Traffic Control Devices referenced in LANL Policy P101-7 Vehicle and Pedestrian Safety. This policy does not specifically address working in parking lots but does discuss Traffic Control Plans in Section 3.4.

5. The FOD and ES-UI should review a better design or layout for the parking lot, consider how to add parking due to volume of traffic during experiments, eliminating blind spots around the liquid nitrogen delivery area, re-locating the large tank, and consider adding a flashing yellow light(s) where appropriate,

6. The UCN office trailer also poses a traffic hazard and should be dismantled and removed. P Division should seek funding to do this.

7. Speed limit sign for parking lot should be installed.

8. The Learning Team write-up should be submitted to the institutional Lessons Learned sharepoint site, the Forklift safety webpage, and added to forklift training.

9. How do we communicate information about tours? Most workers are not at the POTW.

Should Improvement/Corrective Actions be tracked and entered into PFITS? Yes/No

\begin{tabular}{|l|l|l|l|}
\hline Action & Objective Evidence & Owner & Due Date \\
\hline $\begin{array}{l}\text { Enter an FSR to paint one way traffic } \\
\text { arrows on the roadway around tank. }\end{array}$ & $\begin{array}{l}\text { Arrows are painted on } \\
\text { pavement. }\end{array}$ & LFO-DO & $8 / 31 / 2016$ \\
\hline $\begin{array}{l}\text { Work with LANL Traffic Safety } \\
\text { Engineer for placement of traffic } \\
\text { mirrors and enter an FSR to install a } \\
\text { traffic mirror for blind spots. }\end{array}$ & $\begin{array}{l}\text { Mirrors are in place in } \\
\text { parking lot. }\end{array}$ & LFO-DO & $8 / 31 / 2016$ \\
\hline $\begin{array}{l}\text { Buy new traffic cones. The workers } \\
\text { have traffic cones but they are aging } \\
\text { and not very bright. The cones were } \\
\text { used to block the area after the event. }\end{array}$ & $\begin{array}{l}\text { available to } \\
\text { employees. }\end{array}$ & P-25 & $8 / 31 / 2016$ \\
\hline $\begin{array}{l}\text { Include this event in training for } \\
\text { laboratory forklift operators and } \\
\text { include pictures from the event. } \\
\text { Parking lot safety should be added to } \\
\text { the curriculum in accordance with the } \\
\text { Manual on Uniform Traffic Control }\end{array}$ & $\begin{array}{l}\text { Forklift Safety } \\
\text { Fundamentals } \\
\text { Devices referenced in LANL Policy } \\
\text { included in course }\end{array} 20299$ & OSH-ISH & $7 / 31 / 2017$ \\
\hline
\end{tabular}




\section{Parking Lot Event May 2016}

\begin{tabular}{|c|c|c|c|}
\hline $\begin{array}{l}\text { P101-7 Vehicle and Pedestrian Safety. } \\
\text { This policy does not specifically } \\
\text { address working in parking lots but } \\
\text { does discuss Traffic Control Plans in } \\
\text { Section 3.4. }\end{array}$ & & & \\
\hline $\begin{array}{l}\text { The FOD and ES-UI should review a } \\
\text { better design or layout for the parking } \\
\text { lot, consider how to add parking due to } \\
\text { volume of traffic during experiments, } \\
\text { eliminating blind spots around the } \\
\text { liquid nitrogen delivery area, re- } \\
\text { locating the large tank, and consider } \\
\text { adding a flashing yellow light(s) } \\
\text { where appropriate, }\end{array}$ & $\begin{array}{l}\text { A proposed redesign } \\
\text { of the parking lot is } \\
\text { prepared and } \\
\text { improvements in } \\
\text { place. }\end{array}$ & AD-UI & $7 / 31 / 2016$ \\
\hline $\begin{array}{l}\text { The UCN office trailer also poses a } \\
\text { traffic hazard and should be } \\
\text { dismantled and removed. P Division } \\
\text { should seek funding to do this. }\end{array}$ & $\begin{array}{l}\text { A proposal is prepared } \\
\text { and submitted to } \\
\text { ADNHHO's Site } \\
\text { Cleanup Program and } \\
\text { ADEPS management. }\end{array}$ & P-25 & $9 / 30 / 2016$ \\
\hline $\begin{array}{l}\text { Speed limit sign for parking lot should } \\
\text { be installed. }\end{array}$ & $\begin{array}{l}\text { An FSR is submitted } \\
\text { and a speed limit sign } \\
\text { is in place. }\end{array}$ & LFO-DO & $8 / 31 / 2016$ \\
\hline $\begin{array}{l}\text { The Learning Team write-up- should } \\
\text { be submitted to the institutional } \\
\text { Lessons Learned sharepoint site, the } \\
\text { Forklift safety webpage, and added to } \\
\text { forklift training. }\end{array}$ & $\begin{array}{l}\text { The Learning Teams } \\
\text { Write-up is posted on } \\
\text { the LANL Lessons } \\
\text { Learned website. }\end{array}$ & P-25 & $8 / 31 / 2016$ \\
\hline $\begin{array}{l}\text { How do we communicate information } \\
\text { about tours? Most workers are not at } \\
\text { the POTW. }\end{array}$ & $\begin{array}{l}\text { TA54-ST-121-001, } \\
\text { Visitors Tours at TA- } \\
\text { 53, should be } \\
\text { reviewed to ensure the } \\
\text { tour host reports their } \\
\text { tour to } \\
\text { TA53tours@lanl.gov } \\
\text { for inclusion in the } \\
\text { POTD or POTW. }\end{array}$ & $\begin{array}{l}\text { ADEPS - } \\
\text { LANSCE } \\
\text { User Facility }\end{array}$ & $10 / 1 / 2016$ \\
\hline
\end{tabular}


Learning Team Review 2016-0002

Parking Lot Event May 2016

\begin{tabular}{|l|l|l|}
\hline & Based on that review, \\
corrective actions & \\
should be & implemented, such as & \\
administrative & & \\
controls, to ensure & & \\
tours are included in & & \\
the POTD or POTW. & & \\
\hline
\end{tabular}

\section{Should a Lessons Learned/Best Practice be developed? Yes/No}

The Learning Team Report provides this information.

\section{Pictures:}

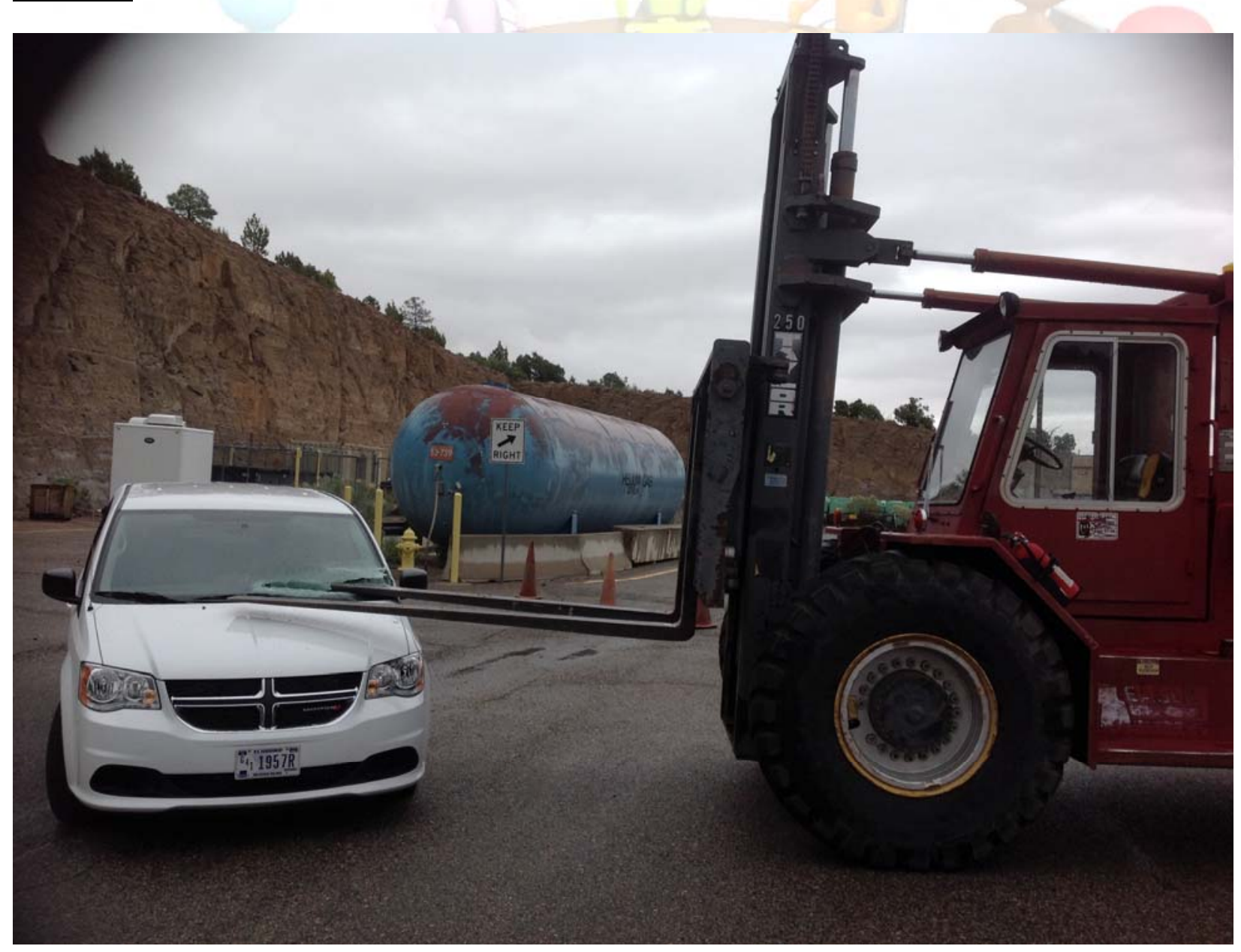

Figure 1 - Post event showing the large tank that obstructed the view of the forklift. 


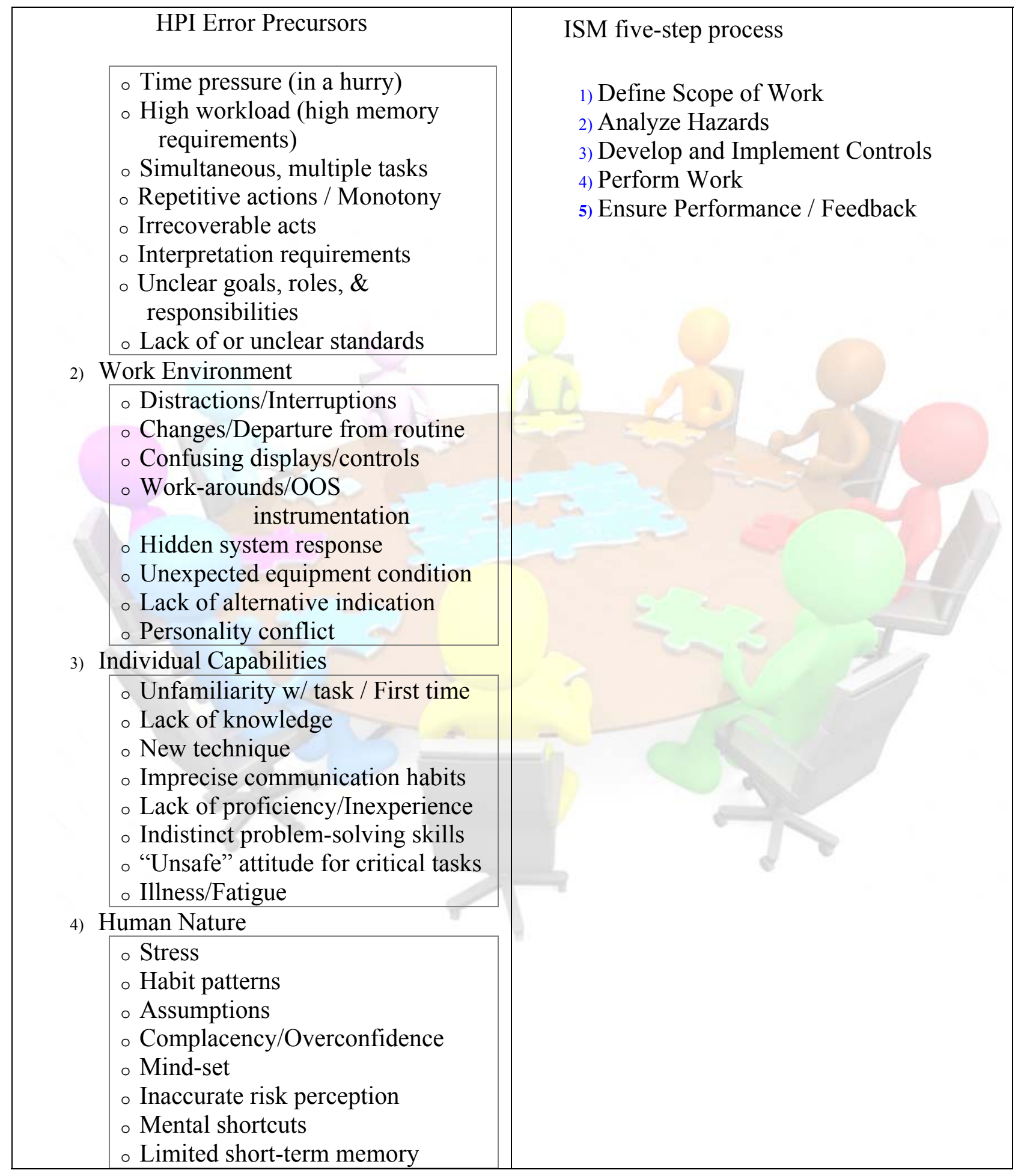




\section{Learning Team Review 2016-0002}

Parking Lot Event May 2016

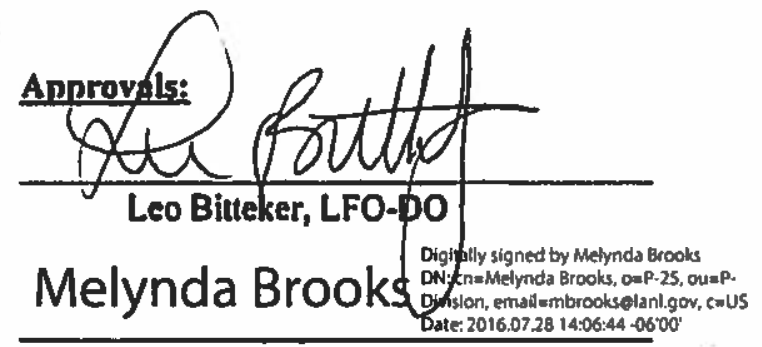

Melynda Brooks, P-25

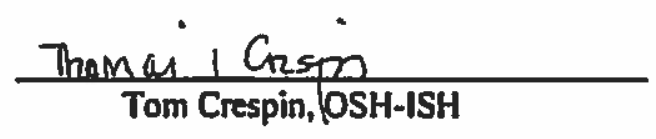

Natalie Romero-

Trujillo

Natalie Romero-Trujillo, ES-UI

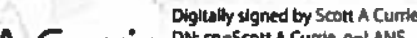

Scott A Currie Dofe: 2016.0801 16:55:32-0600"

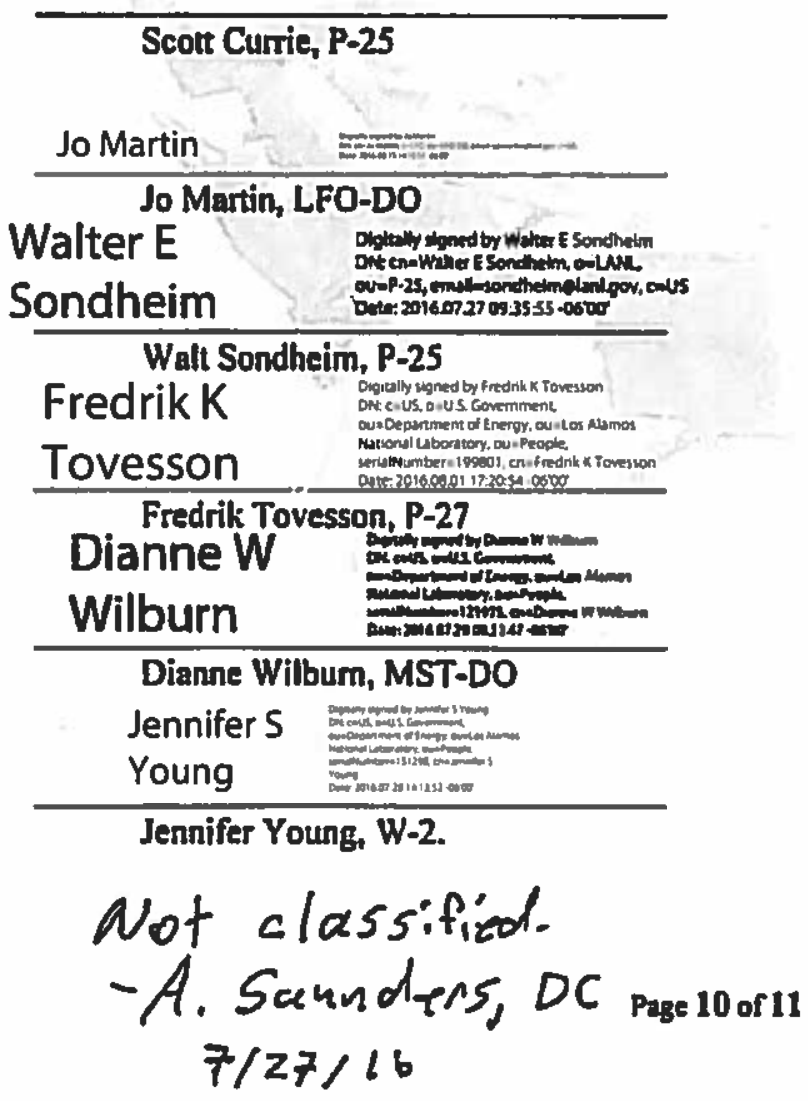

16 Aug 2016

Wate

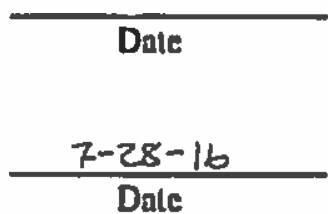

Dale
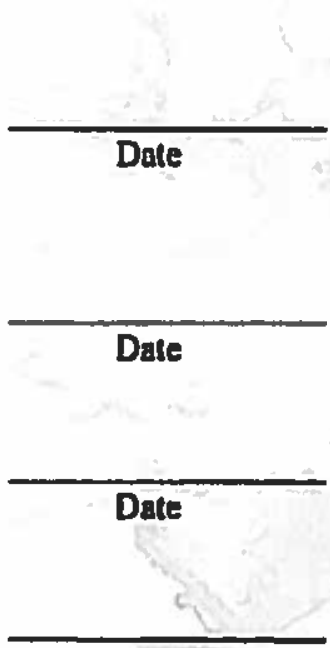

Date

Date

Dale

Date 